\title{
MENINGKATKAN KETERAMPILAN MENARI BALI SISWA TUNARUNGU DENGAN MEDIA KAMUS TARI REJANG DEWA
}

\author{
Kadek Ferna Sulistianingsih ${ }^{1}$, Made Rizky Krisna Desiana ${ }^{2}$, \\ Kadek Putri Suartini ${ }^{3}$, Kadek Suranata ${ }^{4}$ \\ fernasulistyaningsih15@gmail.com ${ }^{1}$, rizkydesiana20@gmail.com ${ }^{2}$, \\ putrisuartini4@gmail.com ${ }^{3}$, sura@konselor.org ${ }^{4}$ \\ PGSD, FIP, Universitas Pendidikan Ganesha ${ }^{1234}$
}

\begin{abstract}
Abstrak: Penelitian ini bertujuan untuk meningkatkan keterampilan menari pada siswa tunarungu dengan berbantuan media kamus tari Bali untuk siswa kelas IV SD Negeri 2 Bengkala. Jenis penelitian ini adalah penelitian kualitatif. Pengumpulan data penelitian ini dilakukan melalui proses dokumentasi, wawancara dan tes yang berupa praktik. Berdasarkan hasil analisis akhir yang telah dilakukan terlihat presentase keterampilan menari kedua siswa tunarungu memiliki perbedaan. Penelitian dengan menggunakan Media Kamus Tari sangat dapat memberikan pengaruh positif dalam meningkatkan keterampilan menari pada siswa tunarungu. Hal ini dilihat dari isi kamus tari menyisipkan gambar dan kode-kode tari yang menarik yang membuat siswa lebih mudah mengerti penerapan tari. Pada media kamus tari ini akan berisikan sebuah gambar gerakan-gerakan yang ada pada tari yang akan ditarikan yaitu tari Rejang Dewa. Gambar-gambar gerakan itu akan dibuat dan ditampilkan secara bertahap sesuai dengan alur gerakan yang ada di tari tersebut. Selain gambar-gambar, dalam kamus ini juga akan berisi tulisan seperti kode-kode di masing-masing gerakan tersebut. Bagi anak tunarungu, untuk menguasai unsur gerak, ruang, tenaga, waktu, dan ekspresi, yang didalamnya termasuk posisi, tingkatan, jangkauan, arah, posisi, dan kecepatan gerak serta formasi, tidaklah terlalu sulit. Dengan melihat model (guru tari) mereka secara bertahap dapat mencontoh dengan baik. Salah satu kesulitan utama yang sering dihadapi adalah suatu kenyataan bahwa anak sulit untuk menyesuaikan dengan tepat antara gerakan dengan irama Melalui media kamus tari diharapkan kemampuan siswa dalam mengembangkan minat dan bakat yang dimilikinya dalam tari teruma pada anak tunarungu, akan tetapi dalam pelaksanaannya,peneliti menemukan perbedaan kemampuan minat dan bakat siswa sangat berbeda pada dua siswa tunarungu. Perbedaan tersebut dilihat dari antusias dan minat siswa tunarungu untuk mengikuti penerapan Tari Rejang Dewa. Jadi, terdapat peningkatan kemampuan menari siswa tunarungu dengan bantuan Kamus Tari Rejang Dewa yang menggunakan kode-kode tangan dan kaki dalam penerapannya.
\end{abstract}

Kata kunci: tunarungu, keterampilan menari, kamus Tari Bali. 


\title{
Kadek, dkk. Meningkatkan Keterampilan Menari Bali... \\ IMPROVE BALI DANCING SKILLS IN DEAF STUDENTS WITH REJANG DEWA'S DANCE DICTIONARY MEDIA
}

\begin{abstract}
This study aims to improve the dancing skills of deaf students with the help of a medium of Balinese dance dictionary for class IV students of SD Negeri 2 Bengkala. This type of research is qualitative research. Data collection of this research is carried out through a process of documentation, interviews and tests in the form of practice. Based on the results of the final analysis that has been done, it can be seen that the percentage of the dancing skills of the two deaf students is different. Research using the Dictionary of Dance Media can greatly provide a positive influence in improving dancing skills in deaf students. This can be seen from the contents of the dance dictionary inserting interesting images and codes that make it easier for students to understand the application of dance. In the media this dance dictionary will contain an image of the movements that exist in the dance that will be danced, namely the Rejang Dewa dance. The pictures of the movement will be made and displayed in stages in accordance with the flow of movement in the dance. In addition to images, in this dictionary will also contain writing like the codes in each of these movements. For deaf children, to master the elements of motion, space, energy, time, and expression, which includes position, level, range, direction, position, and speed of movement and formation, is not too difficult. By looking at the model (dance teacher) they can gradually imitate well. One of the main difficulties that is often faced is the fact that children find it difficult to adjust precisely between movements and rhythms Through the media the dance dictionary is expected to have the ability of students to develop their interests and talents in teruma dance in deaf children, but in practice, researchers find differences the ability of students' interests and talents is very different in two deaf students. The difference is seen from the enthusiasm and interest of deaf students to take part in the application of the Rejang Dewa Dance. So, there is an increase in the dancing ability of deaf students with the help of the Rejang Dewa Dance Dictionary which uses hand and foot codes in its application.
\end{abstract}

Keywords: deaf, dance skills, Balinese dance dictionary.

\section{PENDAHULUAN}

Pendidikan merupakan salah satu upaya mendewasakan dan berguna untuk mengubah tingkah laku manusia atau peserta didik yang dilakukan secara sadar melalui upaya pengajaran dan latihan. Pendidikan bukan hanya hak dan kebutuhan warga atau masyarakat tertentu saja, melainkan hak dan kebutuhan semua warga negara. Hal ini juga merupakan anak tunarungu yang tidak dibedakan dalam hal pendidikan. Mereka 
Kadek, dkk. Meningkatkan Keterampilan Menari Bali... pun berhak untuk mendapatkan pendidikan dan suatu pengajaran yang layak di sekolah walaupun mereka memiliki keterbatasan dalam pendengaran.

Anak dengan berkebutuhan khusus adalah anak yang membutuhkan layanan atau perlakuan khusus untuk mencapai perkembangan yang optimal sebagai akibat dari kelaianan atau keluarbiasaan yang disandangnya. Anak tunarungu merupakan anak yang mempunyai hambatan dengan pendengaran dan masalah bicaranya. Pada umumnya anak yang tunarungu juga memiliki minat dan bakat seperti anak normal lainnya yang mempunyai ketertarikan dan kemampuan terhadap sesuatu. Contohnya dalam olahraga, akademik, seni ataupun kegiatan keterampilan. Kegiatan tersebut juga bermanfaat untuk mengasah dan meningkatkan bakat anak.

Dalam percakapan sehari-hari kondisi anak dengan kelainan pendengaran diidentikkan dengan istilah tuli. Hal ini dapat diakui kebenarannya karena tuna pendengaran dapat mengurangi kemampuannya memahami percakapan lewat pemanfaatan fungsi pendengarannya. Oleh karena itu, pada penderita tuna pendengaran berat berarti semakin besar intensitas ketidakmampuannya untuk menyimak pembicaraan yang memanfaatkan ketajaman pendengarannya, baik dengan bantuan alat Bantu dengar maupun tanpa bantuan alat bantu.

Derajat ketunarunguan seseorang biasanya diukur dan dinyatakan dalam satuan deci-Bell atau disingkat $\mathrm{dB}$. Dilihat dari tingkat gradasinya secara umum dapat dikategorikan menjadi tunarungu dalam arti tuli (deaf) dan tunarungu dikatakan tuli jika hasil tes pendengaran menunjukkan kehilangan kemampuan mendengarnya $70 \mathrm{~dB}$ atau lebih menurut ISO (International Standard Organization).

Salah satu kegiatan untuk meningkatkan bakat anak tunarungu adalah melalui tari. Menari bukan hanya soal keindahan gerak dalam alunan musik, tetapi juga pendidikan, stimulasi ekspresi dan kreasi. Pendidikan tari untuk anak tunarungu dapat menimbulkan kepercayaan diri, serta mengasah kemampuan anak tunarungu. Apalagi pendidikan tari juga termasuk dalam kurikulum. Sehingga dalam prosesnya anak tunarungu lebih banyak menggunakan gerakan dari tubuhnya. Tujuan pembelajaran seni tari bagi pelajar adalah untuk mengekpresikan kembali pengalaman mereka yang lalu secara kreatif, memupuk dan mengembangkan daya ciptanya dan diekpresikan dalam bentuk seni karya tarian kreatif. 
Kadek, dkk. Meningkatkan Keterampilan Menari Bali...

Berdasarkan permasalahan di atas, maka diperlukan suatu upaya untuk mengatasi permasalahan tersebut. Upaya yang dilakukan dalam mengembangkan potensi yang dimiliki oleh anak dengan penggunaan media pembelajaran yang akan bermanfaat bagi perkembangan keterampilan menari siswa. Oleh karena itu peneliti berkeinginan untuk berkolaborasi dengan guru kelas dalam meningkatkan keterampilan menari pada siswa tunarungu. Media yang akan dalam meningkatkan keterampilan siswa tersebut adalah menggunakan media kamus tari.

Media kamus tari ini merupakan salah satu media yang bisa digunakan untuk membantu anak tunarungu yang memiliki minat di bidang seni salah satunya adalah menari. Dalam media kamus tari ini akan berisikan sebuah gambar gerakan-gerakan yang ada pada tari yang akan ditarikan yaitu tari Rejang Dewa. Gambar-gambar gerakan itu akan dibuat dan ditampilkan secara bertahap sesuai dengan alur gerakan yang ada di tari tersebut. Selain gambar-gambar, dalam kamus ini juga akan berisi tulisan seperti kode-kode di masing-masing gerakan tersebut.

Dalam kamus tari menyisipkan gambar dan kode -kode tari yang menarik yang membuat siswa lebih mudah mengerti penerapan tari. Pada media kamus tari ini akan berisikan sebuah gambar gerakan-gerakan yang ada pada tari yang akan ditarikan yaitu tari Rejang Dewa. Gambar-gambar gerakan itu akan dibuat dan ditampilkan secara bertahap sesuai dengan alur gerakan yang ada di tari tersebut. Selain gambar-gambar, dalam kamus ini juga akan berisi tulisan seperti kode-kode di masing-masing gerakan tersebut.

Dengan penjelasan di atas menjadikan guru kolaborator menerima dan ingin menerapkan media kamus tari ini dalam meningkatkan keterampilan menari pada siswa tunarungu. Melalui media kamus tari diharapkan kemampuan siswa dalam mengembangkan minat dan bakat yang dimilikinya dapat meningkat. Hal ini dikarenakan media ini akan berisikan sebuah gambar-gambar gerakan tari dan juga kode-kode dalam menarikan sebuah tarian.

Menurut Windura (2016) “penggunaan gambar dan ilustrasi dalam belajar akan mengaktifkan otak kanan, dan menyeimbangkan dengan otak kirinya. Motivasi belajar siswa menjadi bertambah, hal ini tercermin dari siswa yang bersemangat dan antusias dalam mengikuti penerapan tari. Dengan menggunakan media kamus tari siswa merasa lebih tertarik untuk belajar dan berlatih tari. 
Kadek, dkk. Meningkatkan Keterampilan Menari Bali...

Sebuah tari akan dapat disajikan sesuai konsep garapan, salah satunya berhubungan dengan kematangan teknik tari. Apabila teknik tari tidak dikuasai, maka tari tidak akan dapat mengkomunikasikan konsep garapan kepada penonton. Inti dari permasalahan teknik adalah olah tubuh. Sebab itu, olah tubuh sangat berperanan penting dalam membentuk teknik penari (Indrayuda, 2009:23). Menurut Zahrain (2012) tari adalah salah satu jenis gerak selain senam, bela diri, akrobatik, atau pantomime.

Bagi anak tunarungu, untuk menguasai unsur gerak, ruang, tenaga, waktu, dan ekspresi, yang didalamnya termasuk posisi, tingkatan, jangkauan, arah, posisi, dan kecepatan gerak serta formasi, tidaklah terlalu sulit. Dengan melihat model (guru tari) mereka secara bertahap dapat mencontoh dengan baik. Salah satu kesulitan utama yang sering dihadapi adalah suatu kenyataan bahwa anak sulit untuk menyesuaikan dengan tepat antara gerakan dengan irama.

\section{METODE}

Jenis penelitian yang dilaksanakan adalah penelitian kualitatif. Subjek penelitian adalah siswa Tunarungu kelas IV SD Negeri 2 Bengkala tahun ajaran 2019/2020 yang berjumlah 2 siswa. Desain penelitian yang digunakan yaitu desain A1-B1-B2-B3-A2. Baseline awal (A1) diukur dengan dengan praktik awal tanpa penggunaan kamus sebanyak 1 kali. Kemudian anak dapat diberikan intervensi (B) berupa penggunaan Kamus Tari Bali Rejang Dewa. Intervensi dilakukan secara kontinu sebanyak tiga kali pertemuan. Setelah itu, peneliti mengukur Baseline kedua (A2) dilakukan sebanyak 1 kali pertemuan. Baseline kedua (A2) dilakukan untuk mengukur kemampuan akhir anak selama melakukan pelatihan tari.

Teknik pengumpulan data pada penelitian ini yaitu observasi, wawancara, dokumentasi, dan tes praktik tarian. Teknik observasi digunakan untuk mengetahui permasalahan-permasalahan dalam proses pembelajaran di kelas IV terutama pada kemampuan siswa dalam kegiatan seni. Teknik wawancara digunakan untuk menanyakan sesuatu yang telah direncanakan kepada guru maupun siswa kelas IV. Hasil wawancara dicatat sebagai informasi penting dalam penelitian. Teknik dokumentasi digunakan untuk memperoleh informasi dari bermacam-macam sumber tertulis atau dokumen yang ada pada responden. Instrumen tes yang digunakan untuk 
Kadek, dkk. Meningkatkan Keterampilan Menari Bali... mengukur keterampilan menari siswa dengan melakukan percobaan langsung dengan sendirinya dengan kode-kode gerakan tari yang sudah dibuat.

Teknik analisis data menggunakan teknik analisis data kualitatif yang berupa lembar observasi atau lembar pengamatan. Lembar observasi atau pengamatan ini digunakan untuk merekam data atau keterangan atau informasi tentang diri seseorang yang dilakukan secara langsung maupun tidak langsung. Sehingga, lembar observasi atau pengamatan dapat digunakan untuk mengukur sejauh mana keterampilan menari siswa tunarungu berbantuan kamus tari bali dapat mengembangkan minat dan bakat siswa. Dalam menggunakan lembar observasi atau pengamatan ini juga didukung dengan penentuan indikator pencapaian penerapan kamus tari bali dan rubrik penskoran yang berisikan skor-skor dan keterangan dari skor tersebut.

\section{HASIL}

Kemampuan anak tunarungu untuk mengikuti tarian Rejang Dewa sangat bervariasi, tergantung pada minat dan bakat yang dimiliki anak tunarungu. Semakin tinggi minat dan bakat anak tunarungu dalam mengikuti pelatihan Tarian Rejang Dewa, maka hasil yang ditunjukkan akan semakin meningkat. Kemampuan anak tunarungu yang dideskripsikan pada bagian ini adalah anak kelas IV di SD Negeri 2 Bengkala atas nama Nyoman Rastiti Asih dan Komang Mutiara Lestari. Pelaksanaan Pelatihan Tari Rejang Dewa sangat berperan penting dalam melatih aspek psikomotor anak khususnya keterampilan menari pada anak tunarungu.

Kamus tari ini merupakan salah satu media yang bisa digunakan untuk membantu anak tunarungu yang memiliki minat di bidang menari. Dalam media kamus tari ini akan berisikan sebuah gambar gerakan-gerakan yang ada pada tari yang akan ditarikan yaitu tari Rejang Dewa. Selain gambar-gambar, dalam kamus ini juga akan berisi tulisan seperti kode-kode di masing-masing gerakan tersebut.

Deskripsi umum penelitian memaparkan mengenai hasil penerapan Tarian Rejang Dewa pada anak kelas IV di SD Negeri 2 Bengkala atas nama Nyoman Rastiti Asih dan Komang Mutiara Lestari. Rangkuman hasil pegamatan kegiatan kamus Tari Rejang Dewa pada kedua anak tersebut disajikan pada tabel berikut. 
Kadek, dkk. Meningkatkan Keterampilan Menari Bali...

Tabel 1. Rangkuman Lembar Pengamatan Kegiatan Kamus Tari Rejang Dewa Siswa Tunarungu Kelas IV SD Negeri 2 Bengkala

\begin{tabular}{|c|c|c|c|c|c|c|c|c|c|c|c|c|c|c|}
\hline \multirow{3}{*}{ No } & \multirow{3}{*}{$\begin{array}{l}\text { Nama } \\
\text { Peserta }\end{array}$} & \multirow{3}{*}{ Hari ke- } & \multicolumn{12}{|c|}{ Indikator Pencapaian } \\
\hline & & & \multicolumn{4}{|c|}{ Antusias } & \multicolumn{4}{|c|}{ Ketertarikan } & \multicolumn{4}{|c|}{$\begin{array}{c}\text { Kemampuan } \\
\text { mengikuti gerakan }\end{array}$} \\
\hline & & & $\begin{array}{l}0- \\
44\end{array}$ & $\begin{array}{l}45- \\
64\end{array}$ & $\begin{array}{l}65- \\
84\end{array}$ & $\begin{array}{l}85- \\
100\end{array}$ & $\begin{array}{l}0- \\
44\end{array}$ & $\begin{array}{l}45- \\
64\end{array}$ & $\begin{array}{l}65- \\
84\end{array}$ & $\begin{array}{l}85- \\
100\end{array}$ & $\begin{array}{l}0- \\
44\end{array}$ & $\begin{array}{r}45- \\
64\end{array}$ & $\begin{array}{l}65- \\
84\end{array}$ & $\begin{array}{l}85- \\
100\end{array}$ \\
\hline \multirow{3}{*}{1.} & \multirow{3}{*}{$\begin{array}{c}\text { Nyoman } \\
\text { Rastiti } \\
\text { Asih }\end{array}$} & Hari ke-1 & & 60 & & & & & 80 & & & & 83 & \\
\hline & & Hari ke-2 & & & 83 & & & & & 85 & & & & 85 \\
\hline & & Hari ke-3 & & & & 85 & & & & 90 & & & & 90 \\
\hline \multirow{3}{*}{2.} & \multirow{3}{*}{$\begin{array}{c}\text { Komang } \\
\text { Mutiara } \\
\text { Lestari }\end{array}$} & Hari ke-1 & 40 & & & & & 55 & & & & 55 & & \\
\hline & & Hari ke-2 & & 55 & & & & 55 & & & & 60 & & \\
\hline & & Hari ke-3 & & & 75 & & & & 75 & & & & 80 & \\
\hline
\end{tabular}

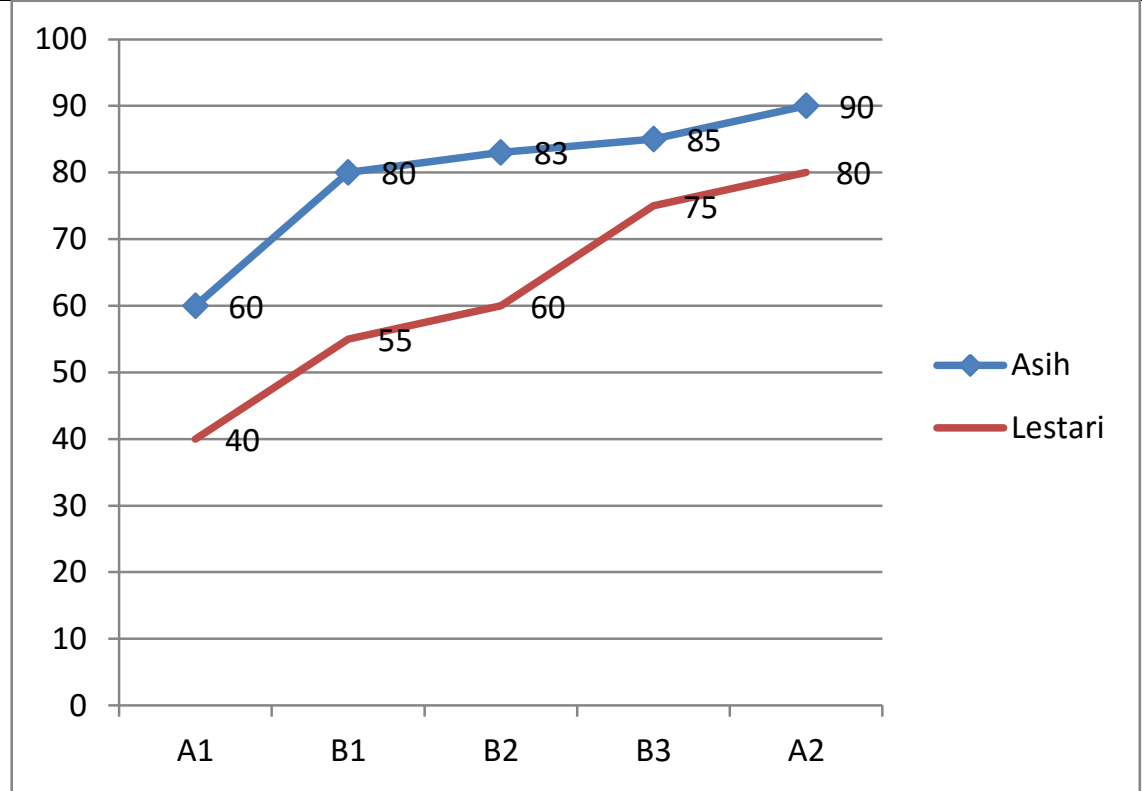

\section{Grafik 1. Pengamatan Kegiatan Kamus Tari Rejang Dewa Siswa Tunarungu Kelas IV SD Negeri 2 Bengkala}

\section{PEMBAHASAN}

Pembahasan dilakukan dengan membandingan kemampuan kedua anak tunarungu yang ada dikelas IV SD Negeri 2 Bengkala. Pembahasan hasil pengamatan dapat dijabarkan sebagai berikut.

Pada saat melakukan penelitian pada dua anak yang berada dikelas IV SD Negeri 2 Bengkala, peneliti menemukan perbedaan kemampuan minat dan bakat siswa sangat berbeda pada dua siswa tunarungu. Pada siswa Nyoman Rastiti Asih pada saat pertama menerapkan kamus tari sangat antusias dan sangat berminat untuk mengikuti penerapanan Tari Rejang Dewa. Setelah berjalan tiga kali penerapan siswa semakit tertarik dan sudah mulai terlihat bakat yang dimiliki. Namun pada siswa yang bernama 
Kadek, dkk. Meningkatkan Keterampilan Menari Bali...

Komang Mutiara Lestari pada saat pertama penerapan anak tersebut terlihat kurang suka dengan tari. Setelah berjalan tiga kali penerapan siswa secara perlahan mulai bisa menari.

Beberapa gerak tari beserta kode tari yang ada pada kamus tari rejang dewa dapat dilihat dibawah ini.
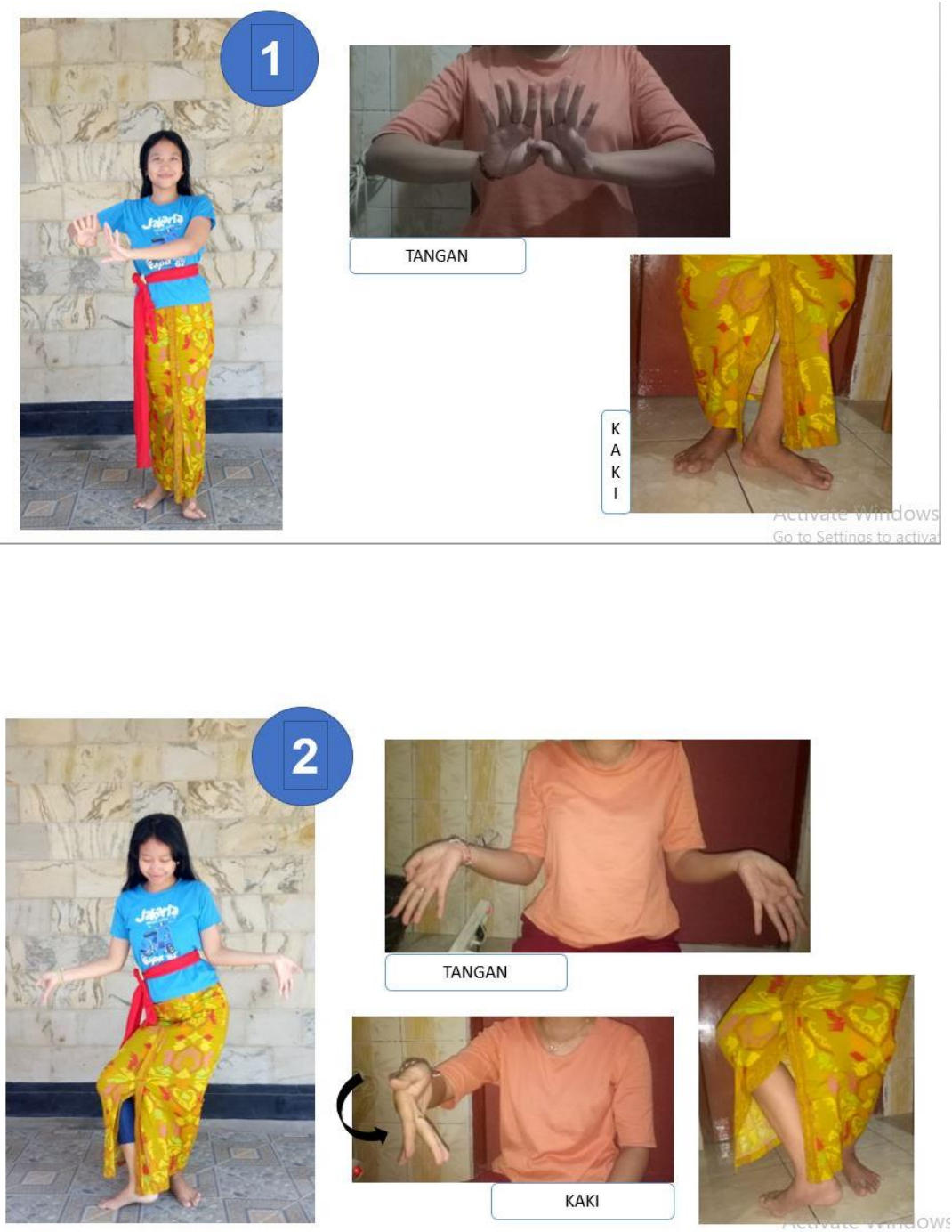
Kadek, dkk. Meningkatkan Keterampilan Menari Bali...

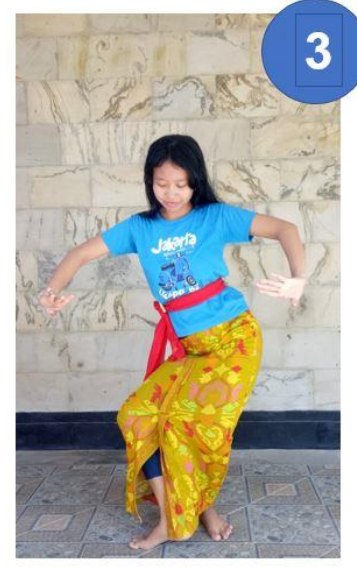

\section{3}

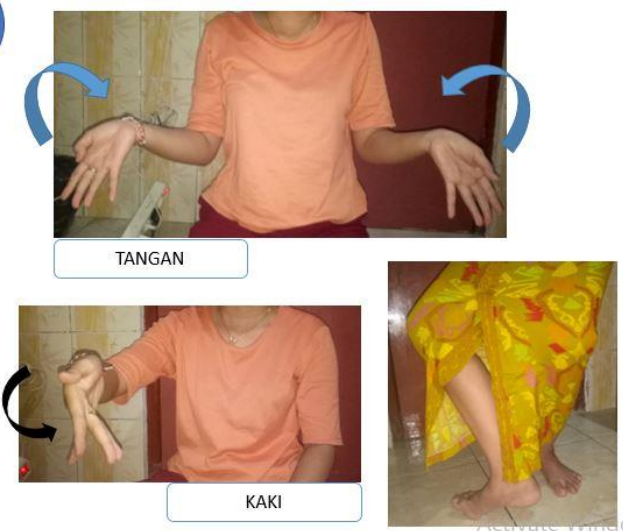

Untuk lebih mendukung, hasil dokumentasi dapat dilihat melalui link ini: https://osf.io/h6j58/?view_only=a1f215cf03cb4b289c60b65c734fa0d1

\begin{tabular}{|c|c|c|}
\hline No & Hari/tanggal & Kegiatan \\
\hline 1. & Senin, 25 Maret 2019 & $\begin{array}{c}\text { Mengirim surat observasi ke sekolah } \\
\text { tujuan sekaligus melakukan observasi } \\
\text { awal mengenai program yang akan } \\
\text { diterapkan }\end{array}$ \\
\hline 2. & Sabtu, 13 April 2019 & $\begin{array}{c}\text { Berkoordinasi dengan kepala sekolah dan } \\
\text { guru inklusi dalam menerapkan program } \\
\text { yang akan dilaksanakan }\end{array}$ \\
\hline 3. & Senin, 6 Mei 2019 & $\begin{array}{c}\text { Mengenalkan gerakan-gerakan dan kode- } \\
\text { kode tari dengan dibantu oleh guru } \\
\text { inklusi dan melakukan praktik awal } \\
\text { menari }\end{array}$ \\
\hline 5. & Selasa, 7 Mei 2019 & $\begin{array}{c}\text { Melakukan gerakan tari secara bertahap } \\
\text { dengan memberikan kode-kode tari } \\
\text { sesuai dengan kamus tari }\end{array}$ \\
\hline 6. & Senin, 13 Mei 2019 & $\begin{array}{c}\text { Melakukan gerakan tari secara penuh } \\
\text { dengan memberikan kode-kode tari }\end{array}$ \\
\hline Sabtu, 18 Mei 2019 & $\begin{array}{c}\text { Kegiatan yang dilakukan yaitu } \\
\text { memberikan kenang-kenangan dan } \\
\text { kamus tari Rejang Dewa kepada siswa } \\
\text { Tunarungu agar bisa digunakan untuk } \\
\text { belajar menari di waktu luangnya. }\end{array}$ \\
\hline
\end{tabular}

Setelah dilakukan beberapa pertemuan dan pelatihan, terdapat beberapa pendapat dari kedua anak yang menjadi objek penerapan media kamus tari ini. Dalam mewawancari pendapat anak mengenai media kamus tari ini kita juga memerlukan 
Kadek, dkk. Meningkatkan Keterampilan Menari Bali...

bantuan guru khususnya yang menjadi perantara komunikasi kita dengan anak tersebut. Anak yang bernama Nyoman Rastiti Asih berpendapat bahwa penggunaan media kamus tari ini sangat membantunya dalam melatih kemampuannya dalam bidang tari dan dia sangat menyukai medianya, sebab isi kamus tari ini lengkap dengan kode-kode untuk melakukan gerakannya baik itu dari gerakan tangan hingga kaki. Sehingga hal tersebut terlihat jelas dalam melakukan kegiatan praktik dan juga menarik dirinya untuk belajar meningkatkan keterampilannya. Pendapat lain dari anak yang bernama Komang Mutiara Lestari yaitu dia memberikan pendapatnya bahwa media kamus tari ini sangat menarik dan sangat jelas gambarnya, sehingga dapat memudahkan dalam menerapkannya. Akan tetapi basic ataupun bakat yang dimilikinya itu bukan dalam bidang tari tersebut. Sehingga dia merasa kurang puas akan apa yang dilakukannya.

\section{SIMPULAN}

Berdasarkan hasil penelitian dapat disimpulkan bahwa penerapan tari untuk melatih kemampuan psikomotor anak tunarungu dengan berbantuan media kamus Tari Rejang Dewa memiliki pengaruh yang sangat baik bagi anak tunarungu. Ketertarikan anak akan tari khususnya Tari Rejang Dewa mulai terlihat. Hal ini dikarenakan dalam media kamus tari ini akan berisikan sebuah gambar gerakan-gerakan yang ada pada tari yang akan ditarikan yaitu tari Rejang Dewa. Gambar-gambar gerakan itu akan dibuat dan ditampilkan secara bertahap sesuai dengan alur gerakan yang ada di tari tersebut. Selain gambar-gambar, dalam kamus ini juga akan berisi tulisan seperti kode-kode di masing-masing gerakan tersebut.

Sehingga anak akan merasa senang dan tertarik untuk belajar sehinga pada saat melakukan penelitian pada dua anak yang berada dikelas IV SD Negeri 2 Bengkala, peneliti menemukan terdapat perbedaan kemampuan minat dan bakat siswa sangat berbeda pada dua siswa tunarunggu. Pada siswa Nyoman Rastiti Asih pada saat pertama menerapkan kamus tari sangat antusias dan sangat berminat untuk mengikuti penerapanan Tari Rejang Dewa. Setelah berjalan tiga kali penerapan siswa semakit tertarik dan sudah mulai terlihat bakat yang dimiliki. Namun pada siswa yang bernama Komang Mutiara Lestari pada saat pertama penerapan anak tersebut terlihat kurang suka dengan tari. Apabila dilatih secara terus menerus, maka anak akan menjadi lebih cepat meningkatkan kemampuannya dalam menari. 
Kadek, dkk. Meningkatkan Keterampilan Menari Bali...

SARAN

Sebaiknya guru konsisten mengadakan ekstrakurikuler seperti tari dan ekstra lainnya terutama kepada anak yang memilki kebutuhan khusus seperti tunarungu agar anak tersebut dapat menyampaikan kegemarannya lewat ekstrakurikuler yang diselenggarakan oleh pihak sekolah dan sebaiknya guru menyediakan sarana prasarana yang mencukupi untuk menunjang kegiatan tersebut agar siswa tunarungu dapat merasa nyaman dalam melaksanakan ekstrakulikuler tersebut.

Untuk pendidik lebih inovatif dalam pembelajaran yang dilakukan terutama pada anak berkebutuhan khusus agar lebih memudahkan dalam pembelajaran anak dan membuat anak lebih nyaman serta tertarik.

\section{DAFTAR RUJUKAN}

Abdullah, N. (2013). Mengenal anak berkebutuhan khusus. Magistra, 25(86), 1.

Haryati, T. 2016. Manfaat Belajar Seni Tari pada Anak Tunarungu dan Dampaknya di Bidang Akademik dan Pengembangan Pribadi. JASSI ANAKKU, 13(1), 56-61.

Hendrilianti, Y. 2016. Model Pembelajaran Tari Kreatif Melalui Pengembangan Bisindo Pada Siswa Tuna Rungu Di Smplb-B Budi Nurani Kota Sukabumi. Jurnal Penelitian Pendidikan, 15(2).

Iswari, Mega. 2007. Kecakapan Hidup Bagi Anak Berkebutuhan Khusus. Jakarta: Departemen Pendidikan Nasional.

M Husna, F., Yunus, N. R., \& Gunawan, A. 2019. Hak Mendapatkan Pendidikan Bagi Anak Berkebutuhan Khusus Dalam Dimensi Politik Hukum Pendidikan. SALAM: Jurnal Sosial dan Budaya Syar-i, 6(1).

Nurbayani, S., Yuliasma, Y., \& Asriati, A. 2017. Menumbuhkan Kreativitas Anak Tunarungu dalam Kegiatan Pengembangan Diri Seni Tari di SLB Negeri 2 Padang. Jurnal Sendratasik, 6(1), 18-27.

Ropitasari, Y. A. 2014. Meningkatkan Kemampuan Menari Tari Balanse Madam Melalui Metode Sas Untuk Anak Tunarungu (Single Subject Research Kelas II SMP di SLB Bundo Kanduang Padang). Jurnal Penelitian Pendidikan Khusus, $3(3)$.

Rosadi, N. 2018. Pengembangan Instrumen Identifikasi Jenis Anak Berkebutuhan Khusus (Abk) Di Sekolah Dasar(Doctoral dissertation, Universitas Muhammadiyah Sidoarjo).

Suharmini, Tin. 2007. Psikologi Anak Berkebutuhan Khusus. Jakarta: Departemen Pendidikan Nasional.

Windura, Susanto. 2016. Brain Management Sreies For Learning Strategy Mind Map Langkah Demi Langkah Cara Paling Mudah \& Benar Mengajar dan Membiasakan Anak Menggunakan Mind Map Untuk Meraih Prestasi. Jakarta: PT Elex Media Komputido Kelompok Gramedia. 